\title{
Miradas innovadoras sobre la interfaz urbano-rural: el plan de Extensión de Ámsterdam, los planes del Condado de Londres y del Gran Londres, y el plan Dedos de Copenhague
}

Patricia López-Goyburu. Universidad de Buenos Aires; Consejo Nacional de Investigación Científica y Tecnológica (CONICET), Buenos Aires, Argentina.

RESUMEN | La expansión urbana se desarrolla a un ritmo y escala sin precedentes, convirtiéndose en un tema de alcance mundial con consecuencias sociales, ambientales y económicas. Actualmente, es difícil establecer un límite formal claro entre lo urbano y lo rural. Los territorios de interfaz urbano-rural (I-UR) tienen el valor de poder actuar como articuladores entre el sistema urbano y el rural. Como consecuencia de ello, en el presente trabajo se pretende establecer una estrategia para detectar cómo se planifica el espacio de I-UR. Para lograr este objetivo, se examinan planes urbanísticos que plantean una relación urbano-rural innovadora: el plan de Extensión de Ámsterdam, el plan del Condado de Londres y del Gran Londres, y el plan de Copenhague. El trabajo presenta una mirada topológica sobre estos documentos emblemáticos, en los cuales se observan tres tipos de soluciones: el establecimiento de un espacio de I-UR entramado, donde el suelo rural se diseña con la misma precisión que el urbano; un "cinturón verde" que establece un límite a lo urbano; y un sistema de "cuńas verdes" que penetran en la ciudad.

PALABRAS CLAVE | crecimiento urbano, periferia urbana, planificación urbana.

ABSTRACT | The urban expansion develops in a rhythm and scale without precedents, becoming a topic of world scope with social, environmental and economic consequences. Currently it is difficult to establish a clear limit between urban and rural. The territories of urban rural interface (I-UR) have the value of being able to act as articulators between the rural and the urban system. As a result of this phenomenon, this article tries to establish a strategy to see how the I-UR space is planned. This is organized through the study of urban plans that raise an innovative urban - rural relation: The plan of expansion of Amsterdam, the County of London plan and the Greater London plan, and the Copenhagen plan. The work presents a topological look on these emblematic documents. In these plans, there are three types of solutions: The establishment of a space of I-UR framework where the rural soil is designed by the same precision as the urban one, a "green belt" that sets a limit to what is urban and a system of "green wedges" which penetrate into the city.

KEYWORDS | urban growth, urban periphery, urban planning. 


\section{Introducción}

La morfología territorial es el resultado de la combinación de sus elementos físicos (tierra, agua y ecosistemas) y de sus elementos antrópicos (caminos, casas, parcelas). El territorio está constituido por la integración del sistema urbano y rural, mientras que el espacio de interfaz urbano-rural (I-UR) es la zona de contacto entre ambos sistemas; es el espacio en el cual las estructuras rurales se subruralizan y las estructuras urbanas se suburbanizan (Eizaguirre, 2001).

Los espacios de I-UR son lugares de tensión que deben ser construidos y estructurados a diferentes escalas. Constituyen la franja que resuelve y materializa los límites espaciales y funcionales en el territorio, y reflejan la capacidad de organización que presentan los terrenos que los espacios de I-UR articulan o limitan. El espacio de I-UR es la zona de acuerdo entre el sistema urbano y el rural (Balcells \& Bru, 2002; Batty \& Longley, 1994; Holl, 1991).

En las ciudades europeas preindustriales, la I-UR se materializaba mediante una muralla que dividía claramente el espacio urbano del rural. En las ciudades industriales, la I-UR quedaba determinada por cuñas o anillos verdes que buscaban el control de los vacíos, o por los planos de ensanche, cuyo objetivo era regular la expansión. En las ciudades coloniales latinoamericanas, la I-UR quedaba establecida mediante la clara delimitación del uso de suelo urbano y rural. Con la Ilustración, la extensión de la cuadrícula intensificó la disolución de los términos estructurantes de la época colonial mediante la regularización de la periferia. Más tarde, se comenzaron a incorporar procedimientos operativos que llevaron al abandono progresivo de la "ideología regular ilustrada" y a la adopción de una "neutralidad técnica" (Aliata, 2006; Favelukes, 2012). Luego, el efecto metropolizador del territorio facilitó el acceso y posterior transformación de los espacios de I-UR.

En esta era de internacionalización de las ciudades, tanto en Europa como en Latinoamérica se puede observar un cambio en la definición de ciudad. La dispersión ha invadido el territorio con ambientes urbanos de baja densidad que no han logrado crear diversidad urbana. La urbanización dispersa ha arrasado con las calidades ambientales, económicas y sociales del medio rural. La acumulación de ambientes urbanos, paisajes de baja densidad y escenarios en red ha producido un territorio discontinuo, desequilibrado y descentralizado. Estas nuevas aglomeraciones urbanas han dado lugar a sistemas urbanos de grandes dimensiones, discontinuos desde el punto de vista territorial, pero integrados en términos económicos y sociales. Se pasó de un espacio enclaustrado con límites definidos a uno fragmentado (Becchi \& Indovina, 1999; Capel, 2003; Folch, 2003; Indovina, 1992).

Las relaciones físicas de dependencia espacial que establecían las murallas, la estratificación funcional o las metrópolis con sus "ciudades satélites", están siendo desfiguradas espacialmente por la globalización a través de los contactos aespacialesatemporales, al hacer que el espacio territorial no sea una barrera físico-temporal. La globalización, la internacionalización de la información y la dispersión urbana han llevado a la conformación de ciudades informes donde los espacios de la movilidad y las redes de información desdibujan las fronteras entre lo urbano y lo rural. Esto dificulta establecer un deslinde formal claro entre el espacio urbano y el rural. Los 
límites de la ciudad están rotos y no son claros, debido a su geométrica ambigüedad (Boeri, Lanzani \& Marini, 1993; Borja \& Castells, 1997; Castells, 1989, 1996; De Mattos, 2010; Font, 2004; Indovina, Fregolent \& Savino, 2005; Mumford, 1956; Woods, 2009).

FIGURA I | Evolución del espacio de I-UR

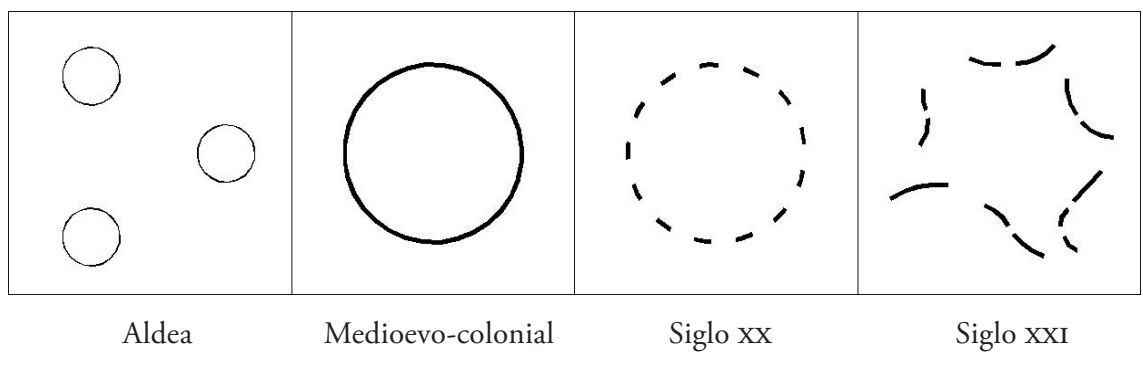

FUENTE ELABORACIÓN PROPIA

Como hemos podido observar, a lo largo de la historia el urbanismo ha buscado actuar en reiteradas oportunidades sobre el crecimiento de la ciudad, sobre la tensión que se genera entre la ciudad que se expande y los esfuerzos por controlarla. Sin embargo, las instituciones no siempre han sido capaces de proporcionar respuestas eficaces para resolver la multifuncionalidad de los espacios de interfaz, que poseen características y dinámicas propias (Buciega, Pitarch \& Esparcia, 2009; López-Goyburu, 2010a). Para que las instituciones puedan llegar a planificar dicho espacio, es necesario encontrar herramientas que permitan actuar sobre el territorio de I-UR, a fin de garantizar no solo su permanencia, sino también la del urbano y del rural. Con tal propósito, en el presente trabajo se analizan tres enfoques innovadores sobre la articulación urbano-rural que se han desarrollado durante el sigloxx, referidos a la forma de ver, pensar y proyectar la articulación urbano-rural: el plan de Extensión de Ámsterdam (1934), el plan del Condado de Londres (1943) y del Gran Londres (1944), y el plan de Copenhague (1947). Este trabajo, que es tributario de una investigación precedente (López-Goyburu, 2010b), tiene los siguientes objetivos:

- Revisar si existen planes urbanísticos que planteen una articulación urbanorural innovadora.

- Analizar y evaluar las estrategias de planificación que plantean dichos planes para los espacios de I-UR.

- Caracterizar y procesar la información significativa relacionada con el territorio de I-UR, para su futura integración en modelos de planificación de dicho espacio.

La metodología aplicada a tales propósitos es de tipo cualitativo, en la medida en que lo que se persigue es explicar las estrategias de intervención en la articulación entre el sistema urbano y el rural. El método de investigación se compone de dos fases. En la primera se realiza una búsqueda de los planes innovadores en la articulación urbano-rural; y en la segunda, se analizan y evalúan dichos planes a través 
de tres miradas (normativa, usos e infraestructuras). Se plantea una estructura en la que estas tres miradas se interrelacionan y se pueden abstraer a un sistema de puntos, líneas y superficies. El periodo de estudio se acota desde la primera revolución industrial hasta el presente, y la investigación se realiza tomando referencias que proporcionan diversos autores.

\section{La estructuración del espacio urbano-rural}

El plan de Extensión de Ámsterdam - 1934

En noviembre de 1934 se presentó el plan de Extensión de Ámsterdam, elaborado a lo largo de casi cinco ańos en el Departamento de Desarrollo Urbano del municipio local. Algunos de los contenidos del mismo habían sido adelantados por el esquema de crecimiento urbano de la ciudad presentado en 1924 por el director del servicio de Obras Públicas, A. W. Bos. Esta propuesta había sido rechazada por el municipio, tras las discusiones generadas en el Instituto Holandés para la Vivienda y el Urbanismo, y en el Congreso de Urbanismo celebrado el mismo año (Galindo, Huls \& Sabaté Bel, 1997; Sabaté Bel, 1989).

\section{Normativo}

FIgURA 2 | Plano del límite municipal de Ámsterdam, 1934

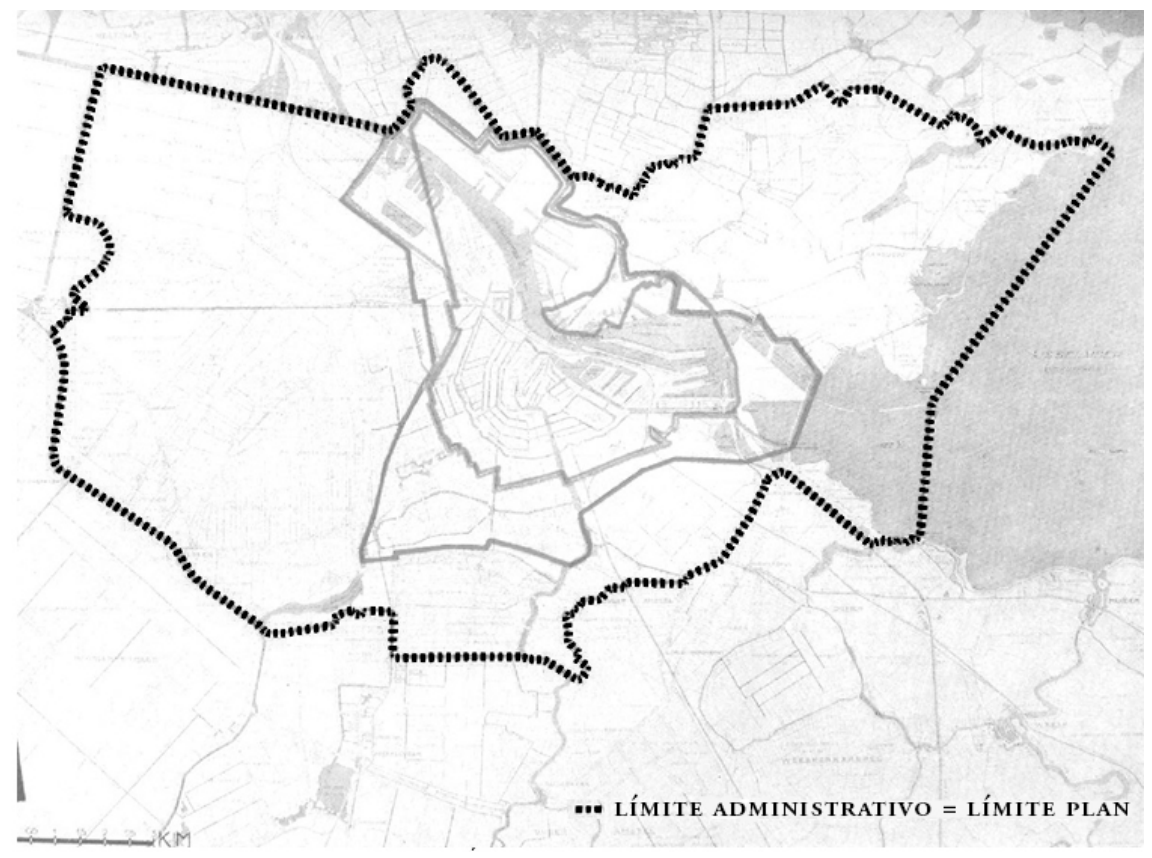

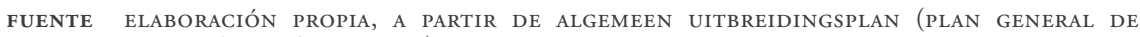
EXPANSIÓN DE ÁMSTERDAM), I 934 
El origen del plan de Extensión de Ámsterdam se puede encontrar en 1928, con la creación de un nuevo Departamento de Desarrollo Urbano y la anexión de terrenos, que permitió cuadruplicar la extensión del municipio (figura 2). El plan se insertó en un contexto en el cual se cuestionaba si la ciudad debía crecer por extensión o por asentamientos satélites independientes, a lo que el plan propuso un modelo urbano centralizado en conexión directa con la estructura centro-ciudad, pero conservando el carácter independiente, la claridad estructural y la utilización de la tipología de baja densidad de la "ciudad jardín" (Sabaté Bel \& Galindo, 2000).

El proyecto ha constituido un esqueleto flexible y adaptable; se limita a dar un patrón de ejes viarios y franjas verdes dentro de las cuales se sitúan los terrenos para las viviendas. Asimismo, fue concebido como un plan procesual y abierto, ya que no determina la imagen final de la ciudad, sino que establece las "reglas de juego". El plan ha entendido que el crecimiento debe ser estructurado por fases y abierto a modificaciones, por lo que en él se dibuja cada opción minuciosamente a fin de extraer de ella parámetros comunes aplicables. Plantea que las propuestas se desarrollen de manera escalonada en el tiempo, por lo que solo fija las dimensiones de la ciudad futura y se asegura algunas decisiones clave, como la dirección de la expansión y las comunicaciones. Ya el urbanista Cornelis van Eesteren, del Departamento de Planificación Urbana de Ámsterdam, había establecido que cuando la ciudad creciera más allá de los límites previstos, se debía hacer otra ciudad, con el fin de salvaguardar tanto el valor del espacio rural como el del espacio urbano (Sabaté Bel \& Galindo, 2000).

\section{Infraestructuras}

En el plan se propuso la ampliación del aeropuerto de Ámsterdam, debido al creciente tráfico aéreo y el aumento del espacio requerido por las aeronaves para el ascenso y descenso. Asimismo, con respecto a la red vial, el plan planteaba una estructura jerarquizada que abarcaba tanto las grandes avenidas como los accesos a las viviendas y estacionamientos, permitiendo, además, una buena y rápida conexión entre las áreas urbanas y rurales (figura 3).

En esta línea, el plan propuso también tres vías de ronda norte-sur: una urbana, una interurbana y una periférica. A este sistema se le superpone otro sistema de conexión viaria con la ciudad existente, a través de vías radiales este-oeste que vinculan el casco antiguo con el espacio rural (figura 4).

El plan ha planteado una mejor conexión del puerto con el mar a través de la ampliación y profundización del canal norte. Sumado a ello, ha buscado establecer un sistema de vías fluviales que se complementen con tres canales de desviación oeste, norte y este-, y la ejecución de un nexo en el sur a fin de mejorar el transporte de mercancías a grandes distancias y la capacidad de comercio de la ciudad. En esa línea, el plan también proponía la construcción de un anillo ferroviario, cuyo principal objetivo era el transporte de mercancías desde y hacia el puerto. 
FIGURA 3 | Plano del sistema infraestructura, Ámsterdam, 1934

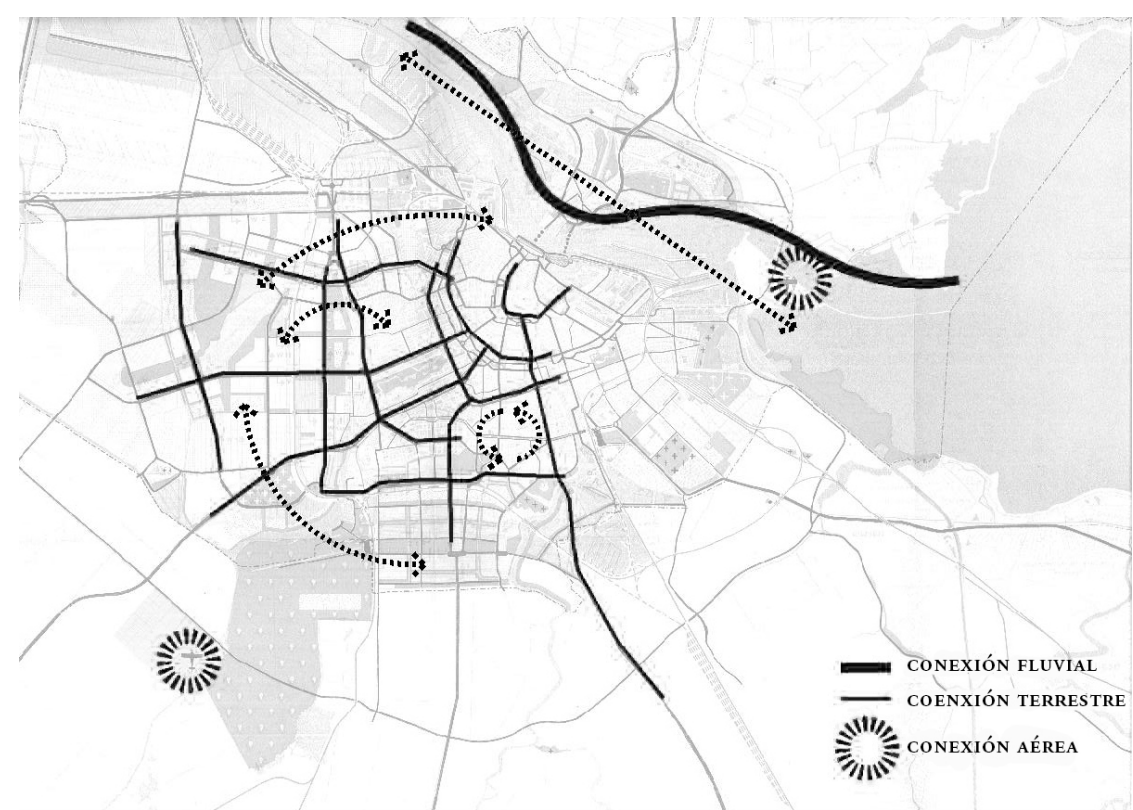

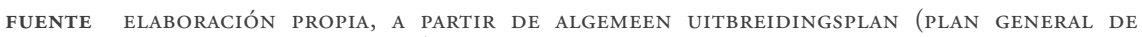
EXPANSIÓN DE ÁMSTERDAM), I 934

FIGURA 4 | Tráfico intermunicipal, Ámsterdam, 1934

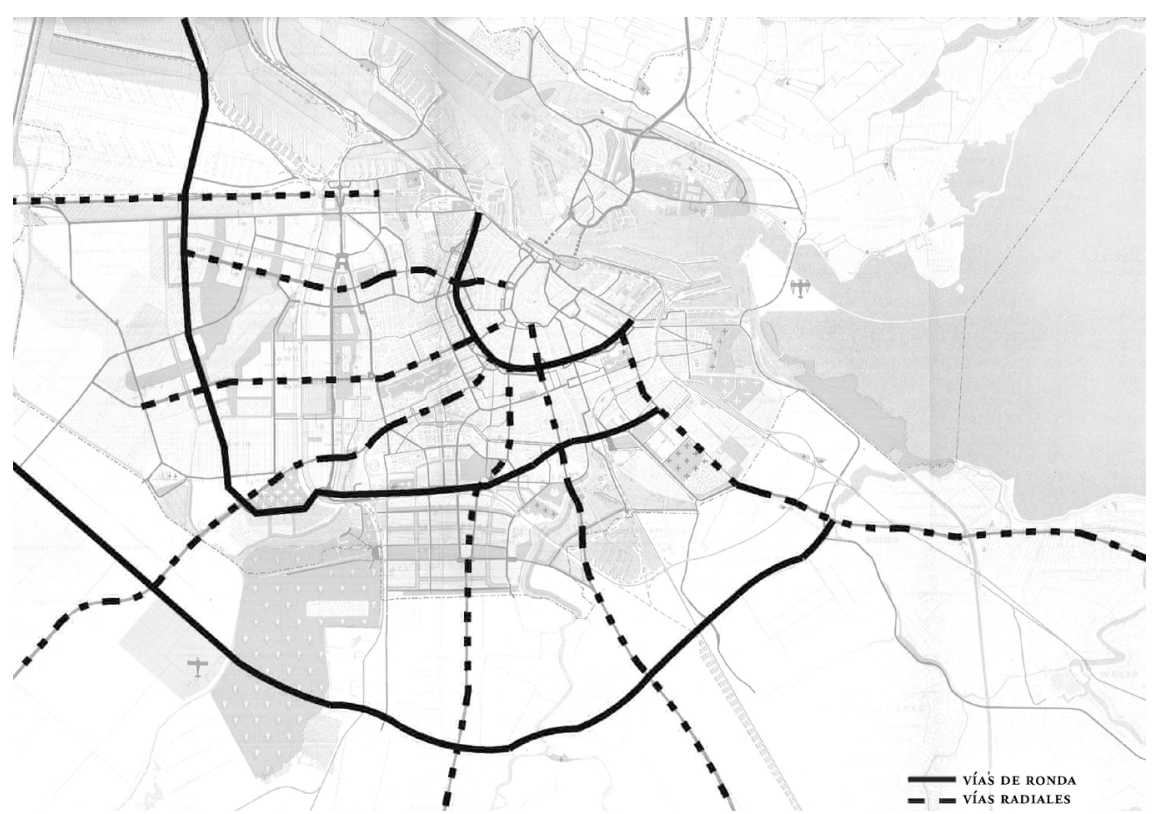

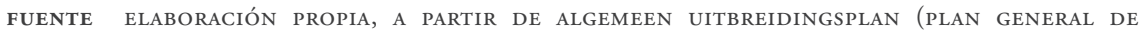
EXPANSIÓN DE ÁMSTERDAM), I 934 


\section{Usos}

El plan vincula la dirección del crecimiento a la extensión del puerto, apostando al mismo tiempo por una organización de la ciudad que permitiera cumplir con las funciones básicas definidas por los Congresos Internacionales de Arquitectura Moderna (CIAM): habitar, trabajar, recrearse y circular. En su propuesta se puede observar que los diferentes barrios de Ámsterdam reflejan la relación existente entre las distintas escalas de planeamiento, y presentan una concordancia con los criterios de composición que permiten mantener la integridad de cada uno de los distritos y del conjunto. Los principales centros de trabajo propuestos se ubican en el noroeste, donde se encontraba el puerto y una zona industrial, y en el sudeste, donde se localizaba otra zona industrial. El plan distingue las diferentes categorías de áreas existentes: industriales, oficinas, comercios, espacios abiertos (grandes complejos de ocio, como el lago Slotemeer o el bosque de Ámsterdam, huertos familiares, áreas agrícolas); plantea la integración de residencia, equipamiento y espacios abiertos, estableciendo la intervención respetuosa en el centro y previendo diferentes formas, dimensiones y tipologías constructivas.

El plan ha evidenciado una disciplinada intervención y rigor en la asignación de los diferentes usos (figura 5). Esta situación tiene su fundamento en la exigencia que impone a los holandeses la creación del propio suelo soporte. El plan descubre los rasgos y peculiaridades del territorio (dirección de las tramas agrícolas, caminos rurales, canales o elementos naturales, como el lago de Sloterplas), incorporándolos como parte activa del proyecto. Esto ha permitido, además del reconocimiento de las lógicas de construcción del territorio, la continuidad de la ciudad con su espacio agrícola (Galindo, 2003; Galindo et al., 1997).

Figura 5 | Plano de zonificación, Ámsterdam, 1934

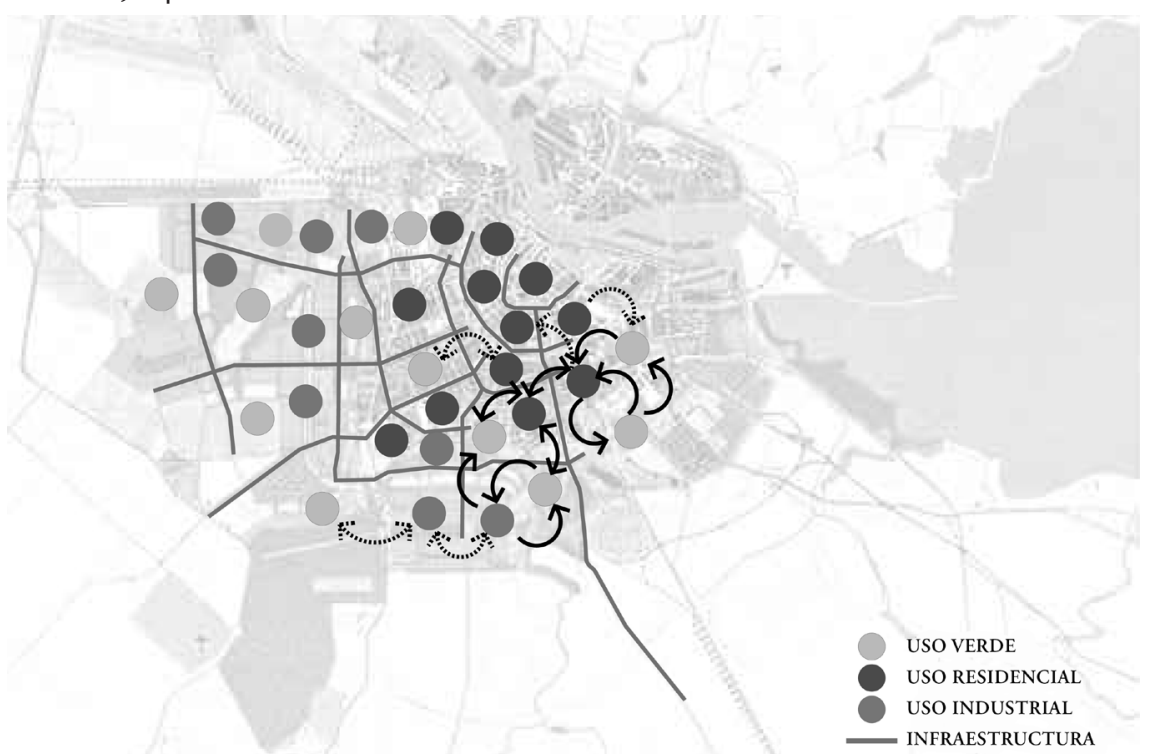

FUENTE ELABORACIÓN PROPIA, A PARTIR DE ALGEMEEN UITBREIDINGSPLAN (PLAN GENERAL DE EXPANSIÓN DE ÁMSTERDAM), I 934 
Junto con lo anterior, el plan ha introducido la agricultura, la ganadería y la horticultura para el desarrollo armónico de la ciudad. El tejido agrícola que propone es un mosaico ordenado de piezas ortogonales relacionadas por caminos y canales y con una estructura uniforme de parcelas estrechas y alargadas. Ubica la horticultura principalmente en la zona occidental de la ciudad, pero incorporando áreas de jardín y huerto en los diferentes distritos. Asimismo, reserva campos para la agricultura y la ganadería e integra pequeñas y grandes áreas recreativas, de fácil acceso vehicular, en bicicleta o a pie.

En relación con el sistema de espacios libres, el plan ha planteado la disposición de tres piezas estratégicas de carácter diferente: un verde central en el espacio del lago Sloterplas, un verde "natural" en torno al Nieuwemeer y una ancha franja en el límite oeste de la ciudad. Estos espacios actuarían como filtro entre el espacio agrícola de los pólderes y la zona urbana de crecimiento residencial, conectados a través de rutas verdes, asociadas normalmente a canales, desde el casco histórico (Galindo, 2003).

El plan ha previsto también barrios autosuficientes, con los equipamientos necesarios para el desarrollo de la vida cotidiana y densidades relativamente bajas (del orden de 35 viv./ha). Si bien estos barrios no requerían del centro, en el plan estaban perfectamente conectados con él a través de una estructura vial jerarquizada. Esta estructura respondía a la idea de ciudad moderna, en la que se asociaba el viario al verde, y los bloques se encontraban exentos y perpendiculares a las mallas viarias. Asimismo, se han proyectado barrios en estrecha relación con la zona rural y propuesto edificios capaces de resolver la transición entre el sistema urbano y el rural, al igual que la colocación de dotaciones como parques, establecimientos deportivos y huertos familiares.

\section{FIGURA 6 | Sector norte del espacio de I-UR, Ámsterdam}

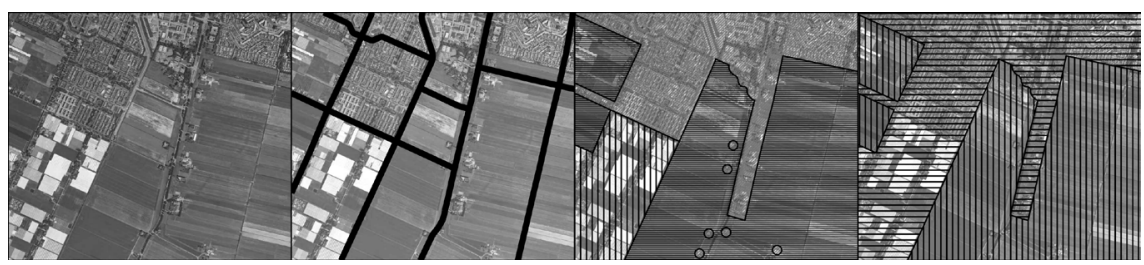

Ortofoto

Infraestructura

Usos

Normativo

FUENTE ELABORACIÓN PROPIA, A PARTIR DE IMAGEN DE GOOGLE MAPS

Plan del Condado de Londres (1943) y el Plan del Gran Londres (1944)

Durante la Segunda Guerra Mundial, Patrick Abercrombie inició el plan del Condado de Londres, aprobado en 1943, para preparar la reconstrucción de la ciudad. El mismo equipo desarrolló en paralelo el plan para el Gran Londres, aprobado en 1944. Estos planes surgieron en un momento en que Londres se encontraba saturada, el tráfico congestionado, la vivienda obsoleta y mezclada con la industria en un espacio comprimido, y los espacios libres mal estructurados (si bien 
había grandes espacios libres, ligados a la realeza, faltaban los de escala intermedia y local, así como las conexiones entre los mismos). Entre ambos planes existía una cierta complementariedad territorial, en el sentido de que la descentralización y desconcentración de la población incluida en el plan del Condado de Londres estaba relacionada con la creación de las nuevas ciudades (New Towns) que planteaba el plan del Gran Londres. Dada tal complementariedad entre ambas propuestas, en el presente trabajo se plantea el análisis de ambos planes para una mejor compresión de la forma de ver, pensar y proyectar el espacio de I-UR de la ciudad.

\section{Normativo}

El condado de Londres corresponde al área central de la aglomeración londinense y está constituido por la ciudad de Londres y 28 distritos (figura 7). Una de las dificultades para orientar el crecimiento de la ciudad ha sido la ausencia de un órgano administrativo responsable de guiar dicho proceso. En 1888, cuando se creó el Consejo del Condado de Londres, la mayor parte de la ciudad estaba dentro de sus fronteras, y tanto el Comité Permanente sobre Planificación de Londres como el Ministerio de Vivienda y Gobierno Local proporcionaron cierta coordinación. Actualmente, Londres y sus zonas circundantes son administradas por un gran número de autoridades por separado (Coppock, 1964).

\section{Figura 7 | Plano del área construida. County of London Plan (Plan del Condado de Londres), 1943}

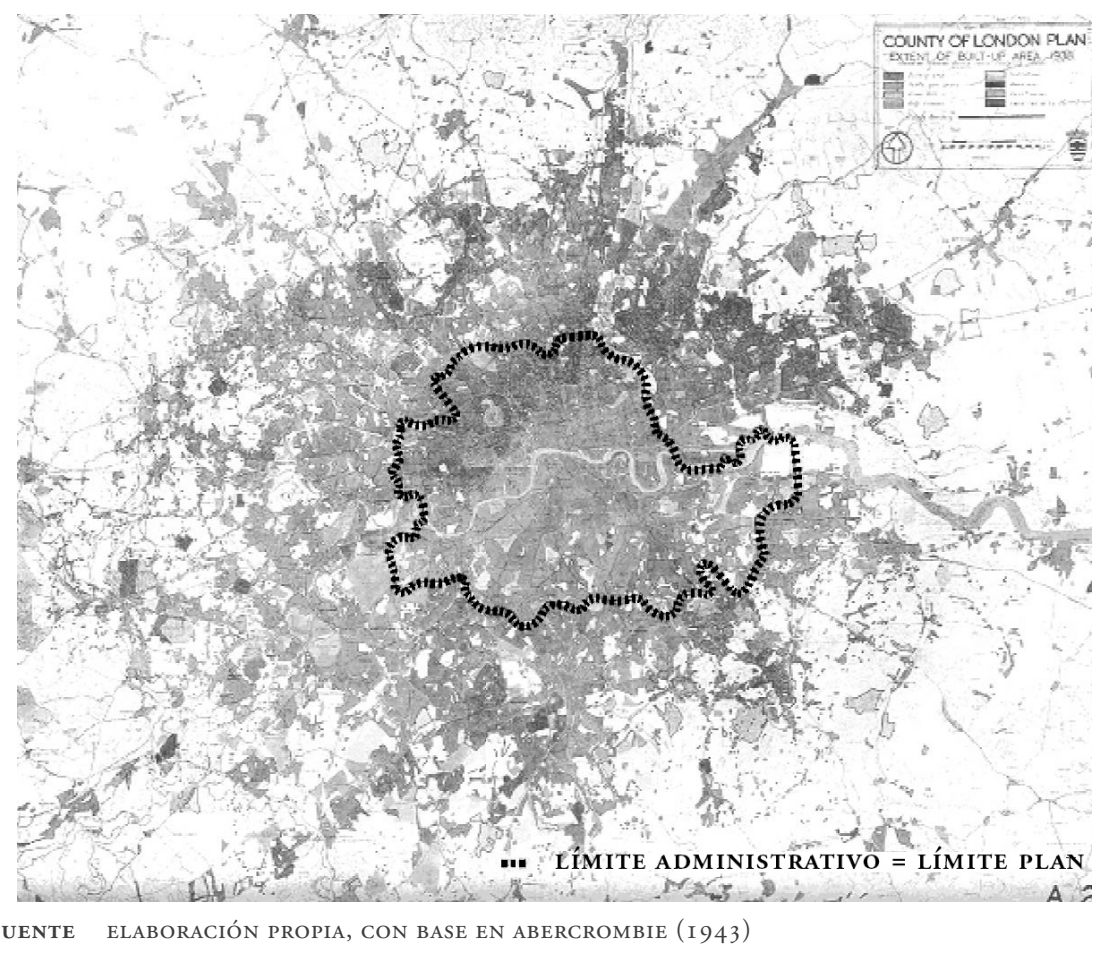


A partir de 1935, el programa del Consejo del Condado de Londres comenzó a preservar las tierras que formaban parte del anillo verde que, según se plantea en el plan del Gran Londres, debía rodear la ciudad y al que se denominó "cinturón verde". La proyección de toda su extensión se alcanzó en 1939, y la ley del "cinturón verde" colaboró en esta tarea. En 1947, la Ley de Planificación Urbana y Rural permitió cumplir con las propuestas que había planteado Abercrombie para el "cinturón verde", definir los límites de la ciudad y establecer el desarrollo urbano en contraste con un espacio abierto (Coppock \& Prince, 1964; Munton, 1983).

A partir de 1950, se puso en funcionamiento el centro de control del "cinturón verde". En el mismo se admite mezclar con el uso agrícola, actividades como escuelas, hospitales, cementerios, campos de golf. A la vez se introdujo otro tipo de actividades, como excavación de grava, industria manufacturera, campamentos del ejército e infraestructuras, como carreteras, ferrocarriles, aeropuertos. En relación con las comunidades existentes que quedaron incluidas dentro del "cinturón verde", se limitó su crecimiento y no se permitió crear nuevos centros urbanos, con excepción de los centros manufactureros u operaciones residenciales motivadas por la posguerra. Los planificadores locales no tienen facultades para cambiar el uso de la tierra, excepto a través de la expropiación (Munton, 1983; Osborn, 1963).

\section{Infraestructuras}

A fin de aliviar la congestión del tráfico, en el plan del Condado de Londres se estableció una jerarquía de carreteras, sistema que definía los cortes físicos y funcionales de la estructura de Londres; el límite de la zona central, el límite de la densidad de los núcleos interiores y el límite entre los suburbios y el espacio rural. El diagrama viario se resolvió con 21 vías radiales (de las cuales 9 tenían consideración arterial) y 3 anillos: el anillo A, interior y que comunicaba todas las estaciones de ferrocarril que parten radialmente de Londres; el anillo $\mathrm{B}$, que articulaba todo el área del Condado y de él partían todas la vías arteriales de carácter radial; y el anillo C, que articulaba el territorio agrícola externo al Condado (figura 8).

En el plan se han combinado carreteras con espacios abiertos, disposición tomada de la propia estructura de Londres, que intercala lo urbano con parques, valles y campos, similar al concepto estadounidense de park-way. Asimismo, proponía un anillo ferroviario para pasajeros subterráneo que conectara las estaciones terminales y dos anillos para el transporte de mercancías, uno interno y otro externo.

\section{Usos}

En los años treinta, el Informe Barlow (1938) estableció que la principal causa de crecimiento de Londres era la industrialización. Esta situación llevó a que el plan del Condado de Londres propusiera racionalizar la localización de las industrias, eliminando las que se encontraban dispersa en el tejido urbano y manteniendo las áreas de concentración industrial, especialmente en la zona del puerto y en las áreas junto al Támesis y el Lee Valley. También se inició el traslado de industrias del Condado hacia el exterior de él, lo cual dio lugar a la propuesta de cuatro anillos por fuera del área central londinense definida en el plan del Gran Londres (figura 9). 
FIgURA 8 | Plano del sistema de carreteras propuesto sobre plano de zonas del Greater London Plan (Plan del Gran Londres), 1944

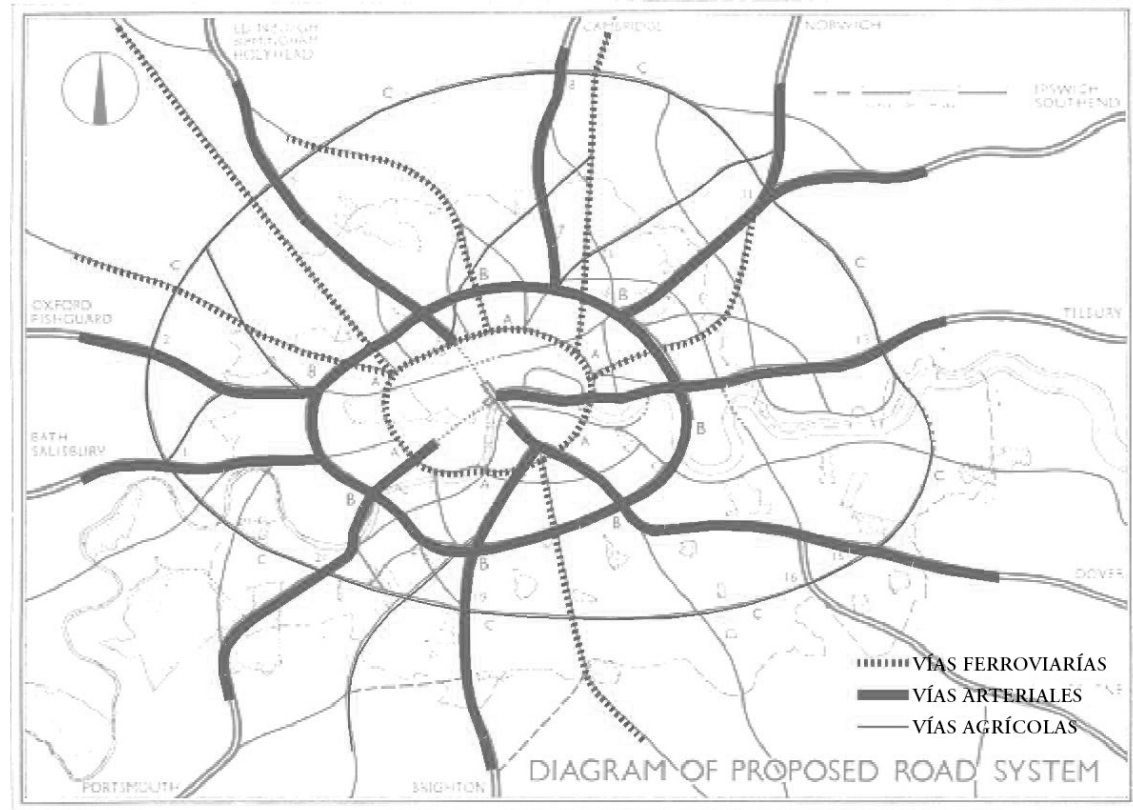

FUENTE ELABORACIÓN PROPIA CON BASE EN ABERCROMBIE (I 944)

El objeto principal del plan del Condado de Londres era desconcentrar y descentralizar el condado; y el del plan del Gran Londres, frenar el crecimiento de la ciudad con la creación de un anillo verde, el "cinturón verde", así como consolidar la localización de 1.100.000 habitantes en un anillo exterior, con la creación de las nuevas ciudades satélite. 
Figura 9 | Plano de zonificación. County of London Plan (Plan del Condado de Londres), 1943

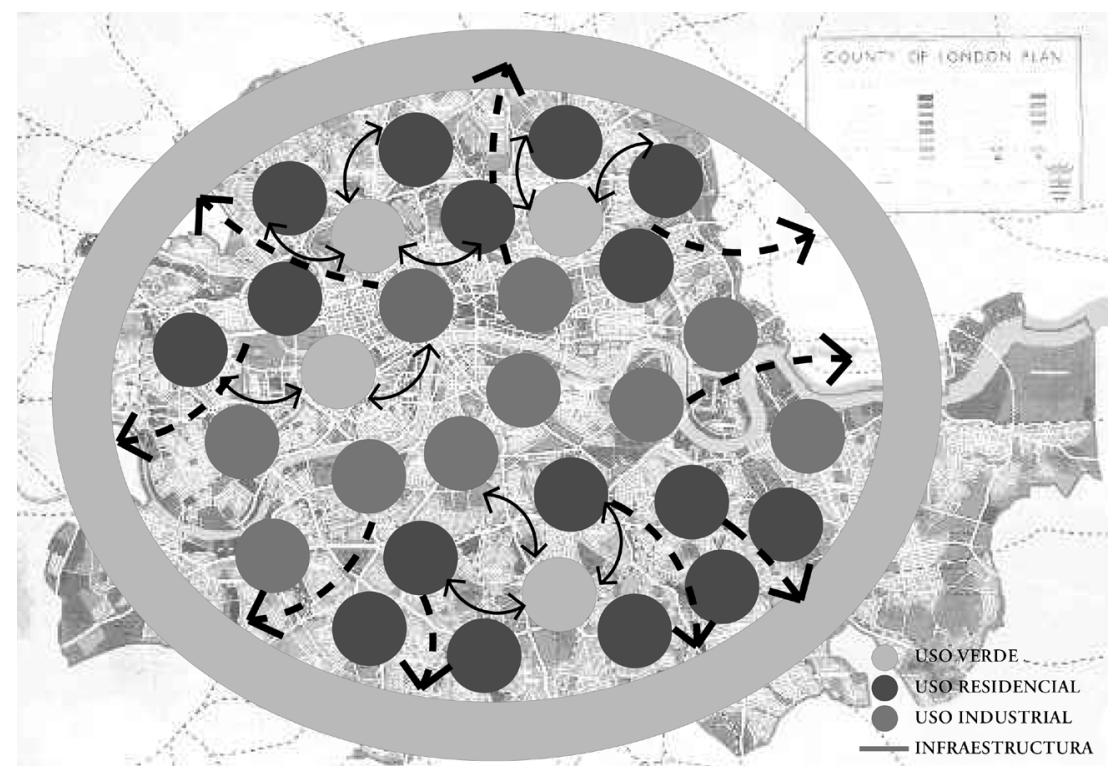

FUENTE ELABORACIÓN PROPIA, CON BASE EN ABERCROMBIE (I943)

Estos anillos se delimitaron en función de la densidad poblacional, la localización de la industria y el uso del espacio abierto. El primer anillo correspondía al área interior urbana, pegada a la ciudad central, y su cometido era desconcentrar y descentralizar el tejido existente. El segundo anillo correspondía al espacio suburbano, representaba el fenómeno del sprawl -expansión urbana-, su cometido era estabilizar la residencia y la industria, y podía ser receptor de población desconcentrada o de industria. El tercer anillo o "cinturón verde" (de 6 millas de ancho) tenía la función de consolidar los usos del espacio libre, no necesariamente públicos pero sí salvaguardados de la construcción. El anillo exterior se destinaba primordialmente al uso agrícola, aunque también era receptor de la población desconcentrada, la cual se ubicaba en las ciudades satélites.

Dentro de los anillos urbano y suburbano, el sistema de espacios libres estaba compuesto por los parques existentes (principalmente grandes espacios ligados a la realeza) y por los espacios intersticiales convertidos en parques, que han hecho posible completar el sistema de espacios libres, proteger y contener a las comunidades existentes, cumplir el estándar de $16 \mathrm{~m}^{2} / \mathrm{hab}$., y permitir a cualquier persona estar a una distancia no mayor a media milla de un espacio verde.

El plan del Gran Londres ha reconocido los espacios abiertos existentes, diferenciando entre aquellos que poseen acceso público de aquellos que carecen de él. Asimismo, ha identificado las áreas de especial valor escénico con una estructura de caminos existentes y cursos de agua, referenciados a la red de transporte público colectivo y a las estaciones de autobús y ferrocarril (todos estos elementos se reflejan 
en los planos "Open Space. Open Space System" y "Open Space. Footpath System"1). El plan no ha propuesto el acceso público a los terrenos del tercer y cuarto anillo más allá de los caminos públicos, pero ha hecho especial mención a la necesidad de reforzar e incrementar estos caminos dentro del "cinturón verde".

En el "cinturón verde", la mayor parte de los espacios abiertos con destino público no son utilizados de manera intensiva y cumplen marginalmente con las necesidades recreativas de los residentes de Londres, principalmente por razones de inaccesibilidad. Aproximadamente el $70 \%$ de la tierra del "cinturón verde" presenta algún uso agrícola, alrededor del $12 \%$ está destinado a bosques, $6 \%$ a uso residencial, $6 \%$ a uso recreativo y solo el $0,2 \%$, a uso manufacturero (Ash, 1972).

El plan del Gran Londres, además de haber delimitado los anillos, proponía una drástica reducción de las densidades existentes desde el interior hacia el exterior: en el área central, fijaba una densidad de 200 hab./ha: en el área subcentral, de 136 hab./ha: y en el área externa, de 100 hab./ha. La densidad va disminuyendo a medida que la ciudad central se acerca al "cinturón verde".

En cuanto a los usos, el plan del Gran Londres también ha prestado especial atención al concepto de comunidad o unidad vecinal, según el cual los núcleos pequeños se relacionan como entidades claras de 5.000-10.000 habitantes, ligadas a una escuela. La definición de estas unidades tenía una doble función: dimensionar correctamente las dotaciones colectivas y liberar el espacio intersticial entre comunidades como zonas verdes.

En esta línea, el plan del Condado de Londres ha propuesto una mixtura de usos dentro del Condado, tanto en el centro como en los suburbios, y ha establecido tres tipos de zonas residenciales (bloques, casas unifamiliares y mixtas), la zona industrial, la zona comercial, la zona de usos especiales y también lo que hoy llamaríamos sistemas e infraestructuras.

FIGURA Io | Sector norte del espacio de I-UR

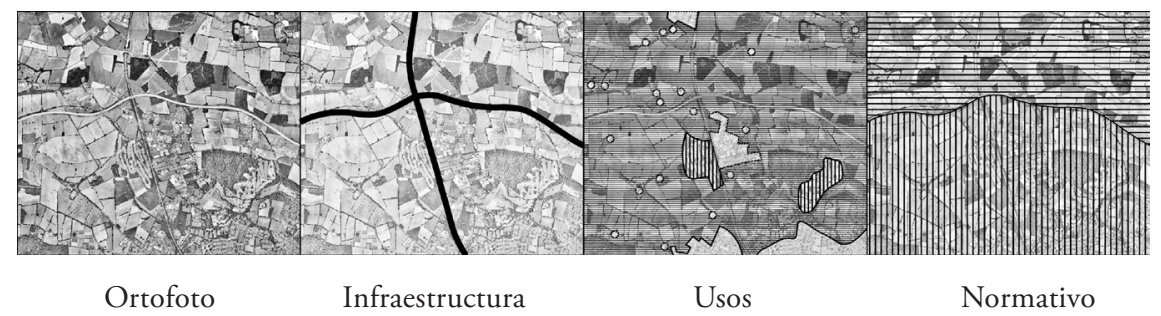

FUENTE ELABORACIÓN PROPIA A PARTIR DE IMÁGENES DE GOOGLE MAPS

Plan Dedos, Copenhague - 1947

En 1947, un grupo de urbanistas asociados al Instituto Danés de Urbanismo elaboró el plan Dedos, que introdujo la base de la planificación regional de Copenhague y fue el primer plan estructural para el área. Su nombre obedece a que el desarrollo se

1 Estos mapas pueden verse en A selection of maps from the Greater London Plan, de Sir Patrick Abercrombie (Londres: HMso / Her Majesty's Stationery Office, 1945) [material cartográfico], en https://searchworks.stanford.edu/view/10627251. 
ha ido produciendo a lo largo de cinco ejes, que se expanden radialmente desde el centro de Copenhague. Debido a que desde el este al suroeste la ciudad está circundada por mar, esos ejes han adoptado la forma de los dedos de una mano, separados entre sí aproximadamente en 135 grados. A partir de ellos se ha desarrollado una red de carreteras y ferrocarriles, mientras los espacios abiertos se han mantenido sin construcciones, como "cuńas verdes" que penetran hasta el centro de la ciudad.

FIGURA I I | Evolución de los planes Dedos, Copenhague, 1947-2007

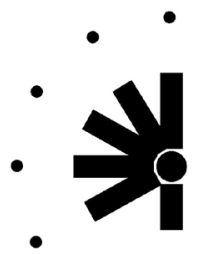

1947

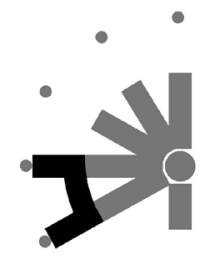

1961

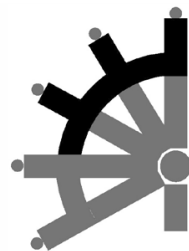

1973

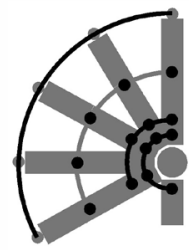

1989

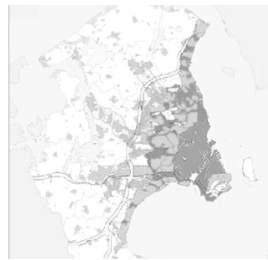

2007

FUENTE ELABORACIÓN PROPIA, CON BASE EN MINISTRY OF THE ENVIRONMENT, DENMARK (2007)

Otro de los rasgos significativos característico del plan ha sido su evolución y adaptación a las necesidades de crecimiento. El plan Dedos de 1947 tomó como base el plan de tráfico de 1926, que establecía el desarrollo urbano a lo largo de líneas férreas que partían en forma radial desde el centro de la ciudad, y se organizaba en torno a las estaciones ferroviarias. En 1961, el crecimiento que estableció el plan de 1947 fue ampliamente superado, debido a la industrialización. Esto dio lugar a asentamientos fuera de los "dedos" planeados, elevado tráfico y presión sobre el área central, debido a la estructura monocéntrica. Tal situación llevó a que el plan de 1961 promoviera el crecimiento urbano en los dedos ubicados al oeste y al sudoeste del centro de la ciudad. Posteriormente, el Plan Regional de 1973 extendió los dedos ubicados al norte del centro de la ciudad, y la vinculación transversal a todos los dedos. Debido al estancamiento del crecimiento urbano, no se consideró necesario elaborar un nuevo plan hasta el Plan Regional de 1989, que se centró en los puntos nodales de tráfico y en la continuación del desarrollo urbano en torno a las estaciones ferroviarias; a la vez, se generó otra vinculación entre los dedos, paralela a la anterior y más alejada del centro de la ciudad. Finalmente, el Plan Regional de 2001 planteó la aparición del sexto dedo en la isla de Amager. Esta isla, en los años noventa, había quedado integrada en la estructura urbana con la implantación de un metro y la conexión fija con el aeropuerto y con Suecia a través de un puente. Hoy los dedos llegan a los pueblos de la provincia, como resultado de la extensión de la urbanización metropolitana y la red eléctrica de ferrocarriles (figura 11) (Ministry of the Environment, Denmark, 2007).

\section{Normativo}

La Ley de Planificación de Dinamarca diferencia las zonas urbanas de las rurales, con una clara frontera entre ellas. En las zonas rurales, el desarrollo se ha regido por normas especiales orientadas a su protección y a evitar la expansión urbana y 
el desarrollo urbanístico no planificados (Ministry of the Environment, Denmark, 2007; Ministry of the Environment, Denmark, 2012).

Figura 12 | Plano del límite administrativo y del límite del plan. Plan Dedos, Copenhague, 2007

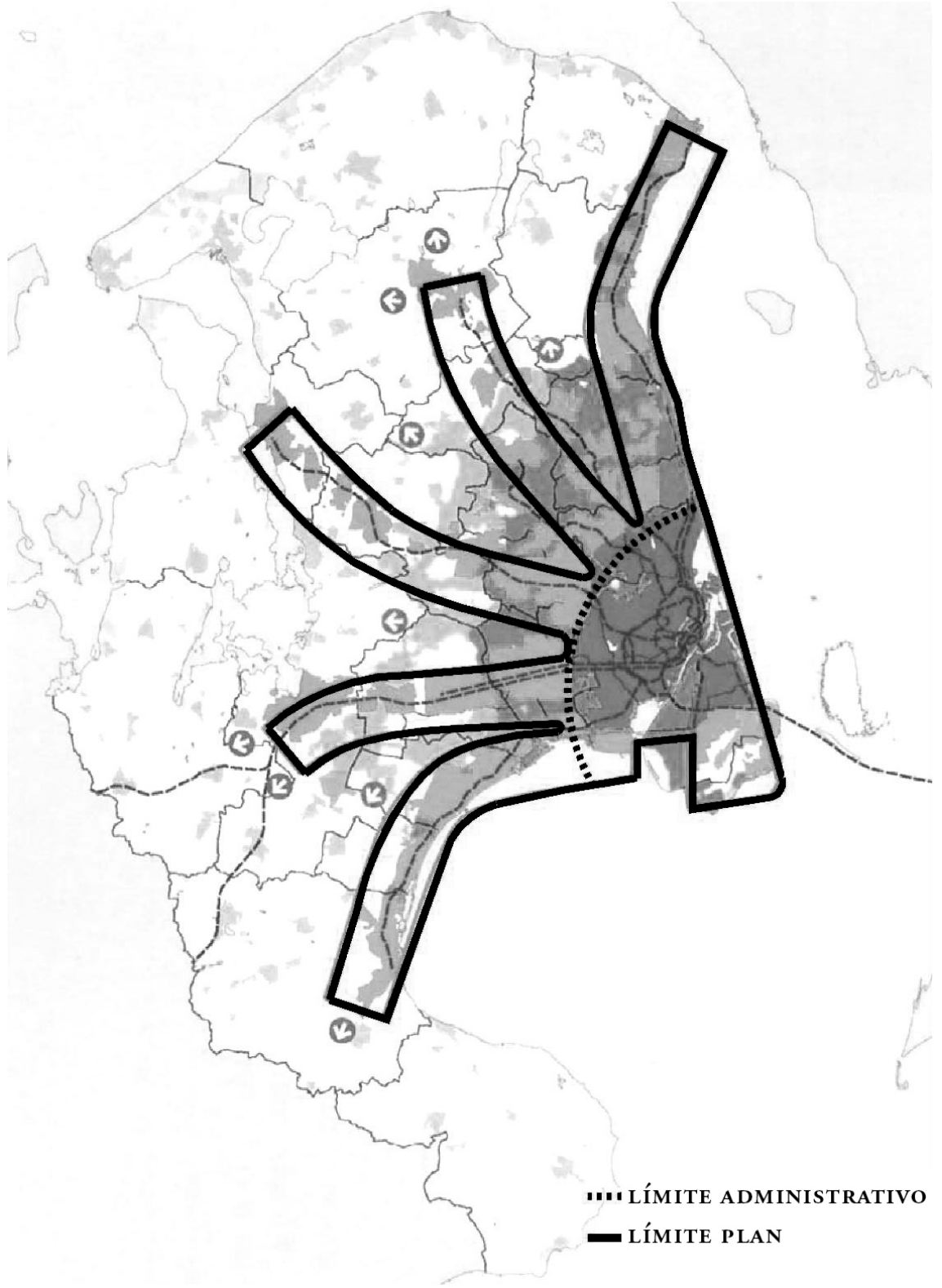

FUENTE ELABORACIÓN PROPIA, CON BASE EN ISHOJ KOMMUNE (2007) 
Los planes municipales han sido los instrumentos a través de los cuales se determina si una zona rural puede ser transformada en zona urbana. Los municipios se han encargado de la planificación de las áreas rurales, la protección del paisaje y la instalación de actividades recreativas, como campos de golf, hoteles, entre otros. Esto ha requerido un diálogo estrecho entre los municipios y la flexibilidad de los planes locales, así como la regulación de factores relacionados con el uso, el tamaño y la ubicación de los edificios, las carreteras y caminos, y las características arquitectónicas de una zona (Ministry of the Environment, Denmark, 2007; Ministry of the Environment, Denmark, 2012).

\section{Infraestructuras}

Uno de los rasgos más importantes del plan Dedos es el uso inteligente de los medios de transporte, los cuales desde los orígenes de la propuesta han constituido la espina dorsal de los dedos y permitido la funcionalidad del área metropolitana. En primer término se encuentran las tres redes de transporte público: el tren de cercanías, el de larga distancia y el metro (figura 13). También cabe destacar la fina malla de autobuses regionales que atienden las áreas rurales y complementan la red ferroviaria. Asimismo, en segundo término, ha estado la movilidad privada, también parte constitutiva de la columna vertebral del plan Dedos, con un sistema mejorado de autopistas en forma de red radioconcéntrica que ha servido de sustento a la movilidad colectiva.

FIGURA I 3 | Red ferroviaria, Copenhague, 2010
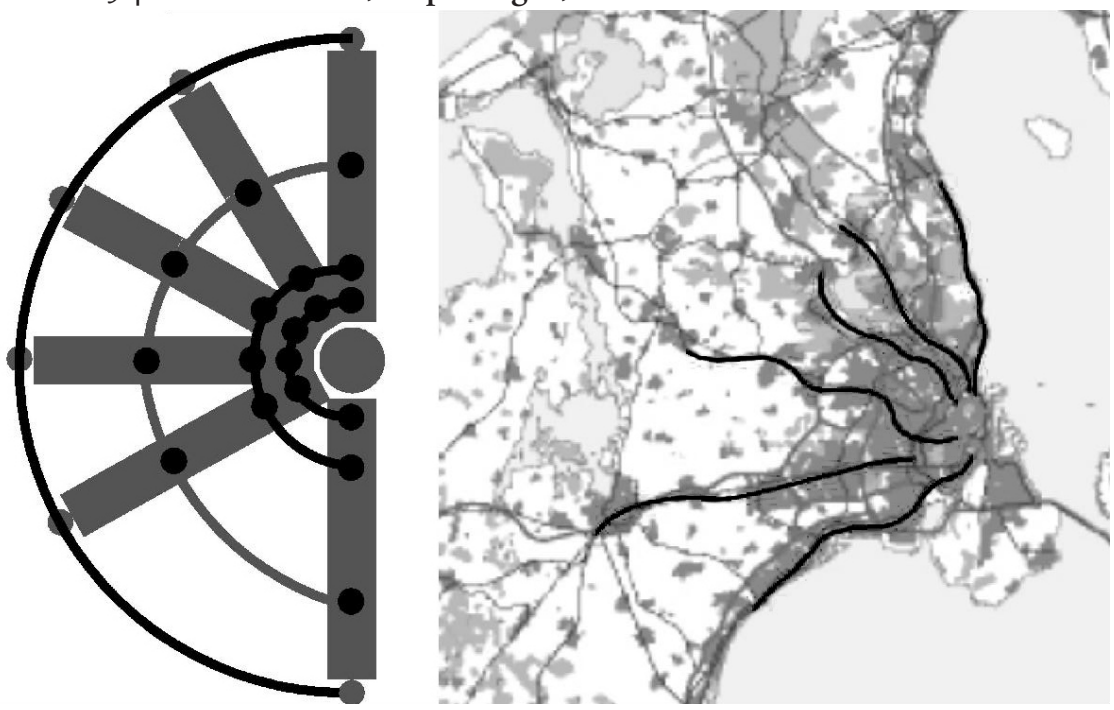

FUENTE ELABORACIÓN PROPIA, CON BASE EN MINISTRY OF THE ENVIRONMENT, DENMARK, 2007.

La infraestructura de carreteras y ferrocarriles constituye la espina dorsal de los dedos. La planificación municipal en el Gran Copenhague ha garantizado la reserva de terrenos para la futura infraestructura de transporte, las instalaciones técnicas, el control del ruido y las zonas de impacto. Copenhague ha estado equipada desde 
mediados del siglo xx con una red ferroviaria que ha manejado el transporte diario de personas hacia y desde el trabajo, la educación u otros destinos.

El ferrocarril en el Gran Copenhague forma una red de aproximadamente 600 kilómetros, con 200 estaciones. Cada día, cerca de 300.000 personas viajan en ferrocarriles desde y hacia Copenhague. En total, la red de transporte público representa aproximadamente 700.000 viajes diarios. Las zonas rurales son atendidas por una compacta malla de rutas regionales de autobús, que complementan la red ferroviaria nacional (Agency for Spatial and Environmental Planning, 2010).

\section{Usos}

En el plan Dedos, la ciudad histórica ha funcionado como centro de la metrópoli y los nuevos crecimientos se han distribuido en nuevos suburbios planificados a lo largo de las líneas férreas radiales. Según se establece en el plan, cada barrio debe tener sus centros comerciales locales, escuelas y demás instalaciones de uso diario. Los centros comerciales se debían establecer en los puntos de conexión entre carreteras, mientras que el principal centro comercial se ubicaría en la ciudad central. El espacio entre barrios se destinaría a parques para uso recreativo. Las tiendas, escuelas y organizaciones de servicios debían situarse alrededor de las estaciones locales. Cerca de ellas, el plan proponía que las personas vivieran en bloques de viviendas, mientras que más lejos había espacio para casas unifamiliares. El espacio abierto quedaba entre los dedos. Asimismo, el plan planteaba que la industria debía encontrarse en la zona de transición entre la palma y los dedos; las zonas industriales estarían vinculadas por vías férreas y por el anillo de la autopista.

El objetivo perseguido por el plan ha sido crear atractivos espacios públicos urbanos y diversos entornos comerciales en las diferentes ciudades. La inversión en nuevos establecimientos comerciales debía apoyar el objetivo de la renovación y regeneración de los distritos de negocios en el centro de la ciudad. El plan ha buscado asegurar que las tiendas sean fácilmente accesibles por todos los medios de transporte, especialmente a pie, bicicleta y transporte público. Asimismo, ha propuesto que las grandes oficinas de trabajo, en general superiores a $1.500 \mathrm{~m}^{2}$, estén situadas en un diámetro de 600 metros de la estación más cercana. Las encuestas, realizadas para el desarrollo del plan, han mostrado que los emplazamientos en torno a las estaciones han inducido a mucha más gente a elegir el transporte público en lugar del privado. El objetivo de la ubicación cerca de las estaciones ha sido reducir el transporte por carretera y, con ello, la carga medioambiental.

Sumado a lo anterior, el plan establecía que en las ciudades entre 20.000 y 40.000 habitantes, el espacio máximo para comercio minorista en el centro de un distrito no excediera los $5.000 \mathrm{~m}^{2}$; en las ciudades con más de 40.000 habitantes, el Ayuntamiento establecería el espacio máximo. Asimismo, el plan fijaba que en un centro local, el espacio máximo para comercio minorista no podía ser superior a $3.000 \mathrm{~m}^{2}$. La Ley de Planificación ha limitado el tamańo de los comercios: $3.500 \mathrm{~m}^{2}$ para tiendas generales y $2.000 \mathrm{~m}^{2}$ para tiendas especializadas en los centros de las ciudades, los centros de los distritos de cada ciudad y los centros secundarios. La regla general ha sido que las nuevas tierras designadas para comercio minorista estén localizadas en el centro de una ciudad. La Ley de Planificación ha incluido algunas 
excepciones a esta norma, como tiendas con mercancías que requieren grandes cantidades de suelo.

La evolución del Plan Dedos y las características del territorio han permitido un desarrollo más acorde en los dedos del oeste y mayores distorsiones en los del norte. Sumado a ello, el crecimiento urbano y la presión sobre el suelo agrícola han supuesto una progresiva especialización del sistema de espacios abiertos. El espacio libre entre los ejes radiales ha sido concebido como zona de recreo para la población urbana y como zona donde mantener el carácter agrícola/natural.

El plan Dedos de 1947 representaba la visión que guiaba el desarrollo urbano, pero abordaba en menor medida el espacio abierto. Los últimos planes regionales han intentado remediar la falta de tratamiento de las áreas rurales ubicadas en el límite con la zona urbana mediante un sistema de espacios abiertos más complejo. Las cuñas verdes interiores han derivado gradualmente hacia parques urbanos, zonas deportivas, jardines o bosques, y las cuñas exteriores mantienen un uso preponderantemente agrícola, sin una planificación comprehensiva ni políticas concretas que eviten la progresiva dispersión. En el último Plan Regional del Gran Copenhague se ha incluido la extensión de las cuñas verdes hacia el espacio agrícola así como nuevos anillos verdes.

FIGURA I4 | Sector norte del espacio de I-UR

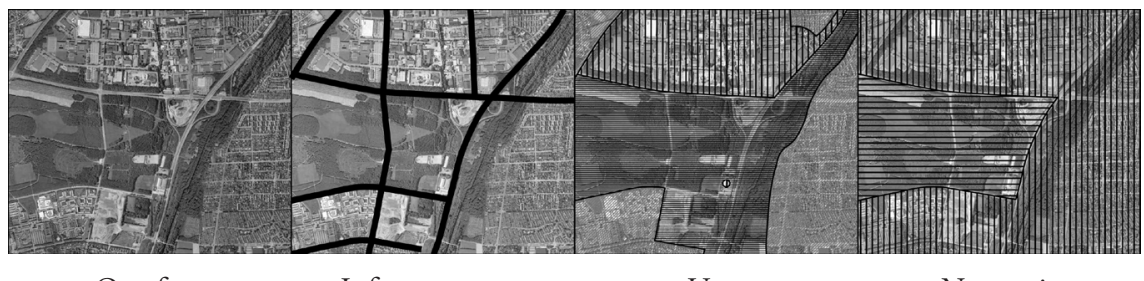
Ortofoto
Infraestructura
Usos
Normativo

FUENTE ELABORACIÓN PROPIA A PARTIR DE IMÁGENES DE GOOGLE MAPS

\section{Conclusiones: Efectos de la planificación del espacio de I-UR sobre el espacio urbano y el espacio rural}

El plan de Extensión de Ámsterdam ha planteado la voluntad de encauzar el crecimiento físico de la ciudad en diferentes fases temporales y como ordenación de piezas autónomas estructuradas a través de la infraestructura soporte. Es un plan en el cual se ha diseñado el suelo rural con la misma precisión que el urbano. Esto obedece a la concepción de que en él no solo se estaba proyectando suelo en relación con las actividades propias de la ciudad, sino dentro de un ámbito territorial más amplio sobre el cual se debía encajar el crecimiento. Concebía la ciudad como un ente perteneciente a un sistema de ciudades y en relación con las ciudades colindantes. Los instrumentos utilizados en el presente trabajo permiten concluir que la división urbano-rural establecida por la normativa del plan de Extensión de Ámsterdam se ha visto acompañada por una clara distribución de los usos sobre el territorio y una precisa disposición de la infraestructura, que se ha comportado 
como un conector de las diversas actividades. Esto ha dado lugar a una interrelación urbano-rural, a un espacio de I-UR entramado.

El plan del Gran Londres, en correspondencia con el plan del Condado de Londres, ha buscado limitar el crecimiento urbano mediante una franja verde cuya función es facilitar el acceso a las zonas rurales, proteger la agricultura, evitar la expansión de las zonas urbanas y mantener una forma urbana reconocible. El "cinturón verde" ha representado un freno al crecimiento urbano, con la posibilidad de convertirse en una herramienta de contención, orden y prestación de servicios urbanos. Sin embargo, la clara demarcación urbano-rural que ha establecido la normativa no se ha visto reflejada en la distribución de usos sobre el territorio. En el plan del Gran Londres, la infraestructura se puede abstraer en un sistema de anillos que delimitan ambos espacios y los ejes que los atraviesan, sin generar una estructura que permita la interrelación urbano-rural. Sin embargo, la mixtura de usos y la disminución de la densidad hacia los bordes que se ha propuesto en el plan del Gran Londres y en el plan del Condado de Londres han reflejado en la práctica una contribución a la delimitación urbano-rural. Estos planes han planteado una I-UR en forma de "cinturón verde".

En el plan Dedos, los espacios abiertos entre los ejes radiales se han mantenido sin construcciones y han penetrado hasta el centro de la ciudad, lo que ha permitido un fácil acceso de la población a los espacios rurales, desarrollados a lo largo de los espacios urbanos. Asimismo, el plan ha buscado concentrar el desarrollo urbano en los dedos de la mano creados por la red ferroviaria, a fin de salvaguardar los espacios verdes entre ellos. Sin embargo, a pesar de la distribución de los usos y densidades que ha establecido el plan, la explosión del coche privado se ha traducido en una demanda de nuevas áreas urbanas y los dedos no se han convertido en lo que proponía el plan. En él, la demarcación urbano-rural planteada por la normativa se ha visto acompañada por la infraestructura, que marca una división entre ambos espacios y ha guiado el crecimiento a través de ejes. Se puede apreciar un estudio detallado de la distribución de los usos urbanos sobre el territorio y una disminución de la densidad edilicia a medida que aumenta la cercanía a la I-UR. El plan Dedos de Copenhague ha planteado una I-UR en forma de "cuña verde".

\section{FIGURA I 5 Estructuración del espacio de I-UR}

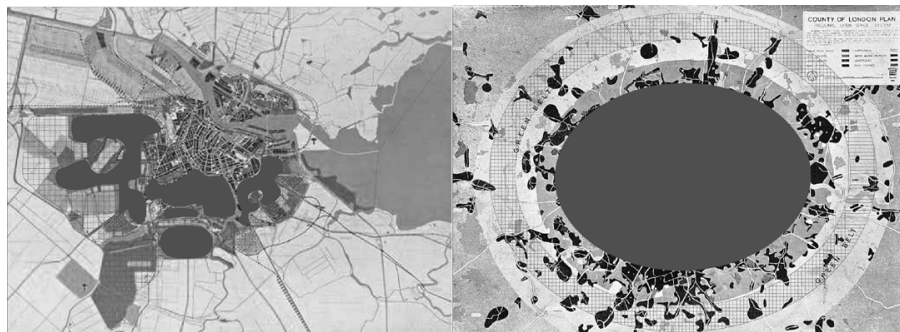

Plan de Extensión de Ámsterdam
Plan del Gran Londres y del Condado de Londres

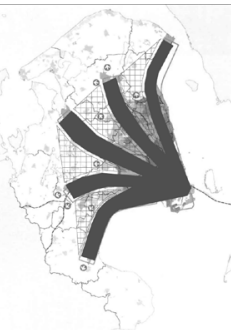

Plan Dedos

FUENTE ELABORACIÓN PROPIA A PARTIR DE IMÁGENES DE ALGEMEEN UITBREIDINGSPLAN (PLAN GENERAL DE EXPANSIÓN DE ÁMSTERDAM), I 934; ABERCROMBIE (I943); ISHOJ KOMMUNE (2007) 
Como hemos podido observar, cada uno de los planes ha afrontado de manera diferente el tema de cómo se acaba la ciudad. En Ámsterdam, se ha planteado un espacio de I-UR entramado, sustentado en la trama viaria y con diseño extremo del espacio urbano y rural. En Londres se ha definido con un "cinturón verde", que ha actuado como medida de contención urbana y que, pese a que no puede ocuparse con ciudad, admite en su interior una mixtura de pueblos, usos agrícolas y ocio. En Copenhague el espacio de I-UR ha estado definido por "cuñas verdes" que penetran en la ciudad.

El encaje territorial de los planes también ha sido diferente. En Ámsterdam se exigía que una vez que se hubiese completado el modelo planteado, se debía construir una nueva ciudad. En Londres, los nuevos crecimientos o "New Towns" debían situarse más allá del "cinturón verde". Y en el modelo de Copenhague, se admite la evolución de la estructura en el tiempo tanto con la creación de nuevos dedos como con la extensión de los mismos.

Sumado a lo antes mencionado, en los tres planes estudiados se puede observar cómo los espacios de I-UR pueden desempeñar un rol articulador y cohesionador entre las infraestructuras de escala global y el territorio de escala local. En esta nueva territorialidad, caracterizada por la dispersión urbana, los espacios de articulación entre el sistema urbano y el rural se presentan como áreas de oportunidad para multiplicar los espacios de contacto. Asimismo, al ser objeto de proyectos urbanísticos, estos espacios de articulación pueden tener un fuerte potencial estructurador del territorio disperso.

En esta línea, el estudio de los planes nos impone algunas premisas proyectuales necesarias de considerar en la planificación de los espacios de I-UR: contemplar las características particulares de cada territorio; conformar una estructura que integre el sistema de infraestructura, asentamientos urbanos, normativa y soporte territorial; divisar el territorio como instrumento de legibilidad y contención; estudiar la superposición de escalas y los procesos oscilatorios entre las mismas.

El trabajo muestra la importancia de conformar una estructura en la que los diferentes elementos (equipamientos, barrios, redes viales, espacios verdes, usos agrícolas, entre otros) y las diferentes escalas que constituyen el territorio, se apoyen. La estructura posibilita que cada uno de los elementos pueda seguir sus propias lógicas de organización, sin dejar de contemplar los hechos específicos de la escala local y las oportunidades de la escala global. La identidad de estos espacios será mayor cuanto mayor sea el grado de orden y homogeneidad del mismo.

\section{Referencias bibliográficas}

Abercrombie, P. (1943). County of London Plan. Londres: Macmillan.

Abercrombie, P. (1944). Greater London Plan. Londres: University of London Press.

Algemeen Uitbreidingsplan (Grondslagen Voor de Stedebouwkundige Ontwikkeling Van Amsterdam) [Plan General de Expansión de Ámsterdam, de Cornelis van Eesteren y Theo Van Lohuizen, Ámsterdam, Holanda, 1934]. 
Aliata, F. (2006). La ciudad regular. Arquitectura, programas e instituciones en el Buenos Aires posrevolucionario, 1821-1835. Buenos Aires: Altuna Impresores.

Ash, M. (1972). A guide to the structure of London. Bath: Adams \& Dart.

Balcells, C. \& Bru, J. (2002). Al lado de. Limites, bordes y fronteras. Barcelona: Gustavo Gili.

Batty, M. \& Longley, P. (1994). Fractal cities. A geometry of form and function. Londres: Academic Press. Versión digitalizada en http://www.fractalcities.org/book/Fractal\%20 Cities\%20Low\%20Resolution.pdf

Becchi, A. \& Indovina, F. (1999). Carateri delle resentí transformazioni urbane. Observatorio città. Milán: Franco Angeli.

Boeri, S., Lanzani, A. \& Marini, E. (1993). Il territorio che cambia: Ambienti, paessagi e imneagini della regione milanese. Milán: Abitare Segesta Cataloghi.

Borja, J. \& Castells, M. (1997). Local y global. La gestión de las ciudades en la era de la información. Madrid: Taurus.

Buciega, A., Pitarch, M. D. \& Esparcia, J. (2009). The context of rural-urban relationships in Finland, France, Hungary, The Netherlands and Spain. Journal of Environmental Policy \& Planning, 11(1), 9-27. http://dx.doi.org/10.1080/15239080902774929

Capel, H. (Dir.). (2003). La cosmópolis y la ciudad. Barcelona: Ediciones del Serbal, Colección La estrella polar, 41.

Castells, M. (1989). La ciudad informacional. Tecnologías de la información, reestructuración económica y el proceso urbano-regional. Madrid: Alianza Editorial.

Castells, M. (1996). La era de la información: Economía sociedad y cultura. Vol. I, La sociedad red. Madrid: Alianza Editorial.

Coppock, J. T. \& Prince, H. (Eds.). (1964). Greater London. Londres: Faber and Faber Limited. County of London Plan. Véase Abercrombie, 1943.

De Mattos, C. (2010). Globalización y metamorfosis metropolitana en América Latina. De la ciudad a lo urbano generalizado. Documentos de Trabajo GEDEUR, 8. Madrid. Publicado en Revista de geografia Norte Grande, (2010)47, 81-104. http://dx.doi.org/10.4067/ S0718-34022010000300005

Eizaguirre Garaitagoitia, X. (2001). La construcción del territorio disperso. Talleres de reflexión sobre la forma difusa. Barcelona: Edicions Universitat Politècnica de Catalunya (UPC). Versión digitalizada en http://duot.upc.edu/publicacions/EIZAGUIRRE_La\%20 construccion $\% 20$ del\%20territorio\%20disperso.pdf

Favelukes, G. (2012). Paradigmas y figuras. Las formas de Buenos Aires (1750-1870). Anales del IAA, 41, 11-27.

Finger Plan. Véase Ministry of the Environment.

Folch, R. (Coord.). (2003). El territorio como sistema. Conceptos y herramientas de ordenación. Barcelona: Diputació de Barcelona.

Font, A. (2004). L'explosió de la ciutat. Morfologies, mirades i mocions. Barcelona: COAC [Col-legi d'Arquitectes de Catalunya ] Publicacions.

Galindo, J., Huls, B. \& Sabaté, J. (Eds.). (1997). La construcció de la ciutat oberta. L'experiència d'Amsterdam. Barcelona: Escuela Técnica Superior de Arquitectura de Barcelona, Universidad Poltéctnica de Cataluña (etsab-upc).

Galindo, J. (2003). Cornelis van Eesteren. La experiencia de Ámsterdam 1929-1958. Barcelona: Fundación Caja de Arquitectos, Colección Arquíthesis, 14.

Greater London Plan. Véase Abercrombie, 1944. 
Holl, S. (1991). Edge of a city. Nueva York: Princeton Architectural Press.

Indovina, F. (1992). La città di fine millennio. Firenze, Génova, Milano, Napoli, Roma, Torino.

$2^{\mathrm{a}}$ ed. Milán: Franco Angeli.

Indovina, F., Fregolent, L. \& Savino, M. (Eds.). (2005). L'esplosione della città. Bercellona, Bologna, Donostia-Bayonne, Genova, Lisbona, Madrid, Marsiglia, Milano, Montpellier, Napoli, Porto, Valencia, Veneto centrale. Bolonia: Editrice Compositori

Ishoj Kommune (2007). Kommuneplan 2007. En http://www.kommuneplan.ishoj.dk/ download/fingerplan_2007.pdf

López-Goyburu, P. (2010a). Estudio y revisión de la interfase urbano-rural para su integración en modelos de planificación territorial y urbanistica. Tesis de Máster, Universidad Politécnica de Madrid.

López-Goyburu, P. (2010b). Buenos Aires, una mirada desde el borde; imagen, idea y proyecto del limite urbano-rural desde su fundación hasta la actualidad. Tesis de Máster, Universitat Politècnica de Catalunya.

Ministry of the Environment, Denmark (2007). Spatial Planning in Denmark. Copenhague: Danish Ministry of the Environment. http://naturstyrelsen.dk/media/nst/ Attachments/Planning_260907_NY6.pdf

http://naturstyrelsen.dk/media/nst/Attachments/Planning_260907_NY6.pdf

Ministry of Environment, Denmark (2012). Spatial planning in Denmark. Copenhague: The Danish Nature Agency. En https://danishbusinessauthority.dk/sites/default/files/ media/2012_planning_eng_guide.pdf

Ministry of the Environment, Denmark (2015). The Finger Plan. A strategy for the developmente of the Greater Copenhaguen Area. Copenhague: Ministry of the Environment, Nature Agency.. https://danishbusinessauthority.dk/sites/default/files/fp-eng_31_13052015.pdf

Mumford, L. (1956). Perspectivas urbanas. Trad. por Demetrio Nañez. Buenos Aires: Emecé.

Munton, R. (1983). London's Green Belt: Containment in practice. Londres: George Allen \& Unwin.

Osborn, F. J. \& Whittick, A. (1963). The New Towns. The answer to megalopolis. Londres: Leonard Hill Books.

Sabaté Bel, J. (1989). En noviembre de 1934... Van Eesteren y el Plan de Extensión de Amsterdam. Urbanismo Revista, (1989)8, 28-39. http://upcommons.upc.edu/ handle/2099/3262

Vejre, H. (2008). Models for safeguarding urban fringe open landscapes - The balance between public and private. Case study of management models for urban green space around Copenhagen. En V. Dewaelheyns \& H. Gulinck (Eds.), Rurality near the City. Proceedings of the international conference and workshops held in Leuven, Belgium, on February 7-8th, 2008 (pp. 51-60). https://www.researchgate.net/ publication/255570571_RURALITY_NEAR_THE_CITY

Vejre, H., Primdahl, J. \& Brandt, J. (2007). The Copenhagen Finger Plan. Keeping a green space structure by a simple planning metaphor. En B. Pedroli, A. van Doorn; G. de Blust; M. L. Paracchini, D. Wascher \& F Bunce, Europe's living landscapes: essays exploring our identity in the countryside (pp. 311-328). Ámsterdam: KNnv Publishing.

Woods, M (2009). Rural geography: Blurring boundaries and making connections. Progress in Human Geography, 33(6), 849-858. doi: 10.1177/0309132508105001 